\title{
Diferencias de género en la convivencia familiar y socialización de estudiantes de Medicina
}

Marisela Rocío Soria Trujano y Edy Ávila Ramos²

\section{Introducción}

Los estudiantes del área de la salud están expuestos a situaciones muy estresantes tanto en el ámbito escolar como en el hospitalario y/o comunitario en el que realizan sus prácticas. Particularmente, los alumnos de la carrera de Medicina cubren horarios extenuantes, tienen sobrecarga de trabajo, alteraciones de hábitos de sueño y de ingesta de alimentos, y afectaciones en sus actividades de distracción y de convivencia con familiares y amigos. Además, en muchas ocasiones estos estudiantes llevan a cabo un internado y/o servicio social en zonas muy alejadas del lugar donde radican sus familiares o son alumnos que, viviendo en provincia, tienen que emigrar de su ciudad de origen para trasladarse y vivir en otra ciudad en la que se encuentra la institución universitaria. Todo esto puede provocar malestares físicos y psicológicos en esta población estudiantil, considerada

1 Facultad de Estudios Superiores Iztacala, UNAm. Psicología Clínica.

2 Facultad de Estudios Superiores Iztacala, unam. Psicología. Métodos Cuantitativos. 
muy vulnerable. Huaquín y Loaíza (2004) concluyen que en el área de la salud, la carrera con mayor demanda de exigencias es Medicina, y por ello los estudiantes mantienen a lo largo del ciclo escolar un nivel moderado de estrés. Además, se han realizado estudios en lo que se observa que las mujeres presentan mayor nivel de estrés académico que los hombres (Marty, Matías, Figueroa, Larraín y Cruz, 2005; Valenzuela y Fraijo, 2011). En este panorama, el apoyo social adquiere relevancia y la familia puede proporcionar afecto y conductas reales de ayuda, con lo cual los jóvenes pueden afrontar las situaciones estresantes. La familia es un espacio en el que se establecen relaciones que favorecen el desempeño social de sus integrantes y en el que se pueden adquirir habilidades que permitan afrontar y resolver problemas, así como para adaptarse a las situaciones ambientales. El rendimiento académico de los estudiantes puede verse afectado por las tensiones familiares; la familia tiene efectos en la motivación para estudiar y es un medio en el que se generan expectativas de éxito académico. Hay estudios que arrojan datos que indican que las buenas relaciones interpersonales dentro de la familia que reflejan convivencia basada en el apoyo repercuten positivamente en el rendimiento académico de estudiantes universitarios de carreras del área de la salud (García, 2005; Paz, Rodríguez y Martínez, 2009). Se han reportado estudios que indican que contar con una familia integrada en la que se establezca la comunicación favorable para todos los miembros repercute efectivamente en la autoestima de los jóvenes, lo cual tiene efectos positivos en la respuesta académica de éstos (Petra, Espinosa, Esquivel y Valle, 2006). Por otro lado, las relaciones entre compañeros de escuela adquieren importancia en el sentido de que los estudiantes pueden compartir sus problemas académicos, puesto que tienen conflictos similares y pueden ayudarse mutuamente (aclarar dudas, apoyo para realizar trabajos o para solucionar conflictos entre compañeros y/o con algún profesor, etcétera). Asimismo, las actividades de distracción favorecen las relaciones sociales que pueden promover el apoyo y un mejor afrontamiento al estrés académico. Feldman et al. (2008) han observado que el apoyo de amigos se relaciona con 
la intensidad de estrés académico en el caso de la población femenina; mientras que en lo que respecta al género masculino, es más importante el apoyo social en general. Así, surgió el interés por realizar el presente estudio cuyo objetivo fue evaluar las relaciones familiares y sociales de estudiantes de la carrera de Medicina analizando las posibles diferencias de género.

\section{Método}

Participantes

Se evaluaron 200 estudiantes universitarios de la carrera de Medicina de la Facultad de Estudios Superiores Iztacala de la Universidad Nacional Autónoma de México, que cursaban segundo, cuarto, sexto u octavo semestre. Esta muestra estuvo conformada por 105 mujeres y 95 hombres. Todos ellos vivían en la Ciudad de México o en el área metropolitana. Se les contactó por vía de sus profesores, siendo la muestra no probabilística, de tipo intencional.

\section{Instrumento}

Se diseñó una escala tipo Likert de 35 ítems y 5 códigos de respuesta: muy frecuentemente, frecuentemente, pocas veces, casi nunca y nunca. El Alpha de Cronbach fue de .788.

\section{Procedimiento}

Se obtuvo el consentimiento informado de los participantes respetando su anonimato, haciendo de su conocimiento el uso de la información obtenida para presentarla en eventos científicos y/o para publicar. Se evaluó a los estudiantes de manera grupal en sus salones de clase. 


\section{Resultados}

Se aplicó la prueba t de Student para muestras independientes con el fin de establecer posibles diferencias entre géneros y las relaciones de interés. Las comparaciones entre el género y las relaciones no muestran diferencia significativa: t198 $=1.385 \mathrm{p}>$ .05. Al revisar los porcentajes obtenidos, se pudo observar que la muestra del género femenino alcanzó un porcentaje mayor de participantes (60\%) con problemas para socializar, lo que significa que se relacionan poco con familiares y con otros jóvenes y tienen problemas con ellos. En el caso de la muestra del género masculino, el porcentaje alcanzado (45\%) indicó que casi la mitad manifestó problemas de socialización. Al llevar a cabo las comparaciones por género en cuanto a cada uno de los ítems de la escala para socialización, se encontró diferencia significativa entre géneros en uno de ellos: "Tengo problemas para relacionarme con mis compañeros de escuela": t198 $=2.24 \mathrm{p}<.05$, siendo las mujeres las que reportaron más dificultades. En lo que respecta a las relaciones familiares y al género, no se detectaron diferencias t198 $=.437 p>.05$. Los datos porcentuales denotaron que la mayoría de los participantes (65.7\% de mujeres y $65.3 \%$ de hombres) reportaron un nivel bajo de problemas de interacción, lo que indica que conviven con su familia de origen y con la familia extensa sin conflictos. No obstante, se dieron casos de estudiantes en los que se detectaron problemas en la interacción con algunos miembros y para hacer compatibles las responsabilidades académicas con las familiares, lo cual pone en riesgo el apoyo que puede recibirse de este núcleo (34.3\% de mujeres y $33.7 \%$ de hombres). Al analizar los resultados por cada ítem de la escala para relaciones familiares, tampoco se obtuvo diferencia significativa en cuanto a géneros.

\section{Conclusiones}

Gran parte de la muestra general manifestó problemas en las relaciones con compañeros de escuela y con familiares, aunque 
en el ámbito familiar fueron menos los participantes que señalaron tener conflictos. Se puede decir que los alumnos conviven frecuentemente con su familia de origen y con la extensa, pero una tercera parte de todos los estudiantes evaluados tiene dificultades con algún(os) miembro(s) de su familia y tiene problemas para hacer compatibles sus responsabilidades académicas con las familiares, lo cual pudiera poner en riesgo el apoyo que se recibe en este núcleo. Por otro lado, sólo la mitad de los estudiantes de ambos géneros señaló que comparte actividades de distracción con otros jóvenes, lo cual puede deberse a la falta de tiempo debido a la sobrecarga de trabajo académico. Muchos hombres y mujeres indicaron tener problemas para interactuar con algunos compañeros y con algunos miembros del profesorado, habiendo mayor problema en la muestra femenina. Se sugiere estudiar factores como la carencia de habilidades sociales y posible discriminación de género y acoso. Además, resulta interesante evaluar la posible correlación entre las interacciones evaluadas y el rendimiento académico así como la presencia de estrés, pudiéndose diseñar talleres para su afrontamiento. Adquiere relevancia la organización del tiempo libre para fomentar la socialización y la convivencia con la familia. Los jóvenes que estudian la carrera de Medicina necesitan una formación excelente en un ambiente escolar óptimo, debido a que en un futuro dependerá de su buena ejecución el bienestar de muchos pacientes.

\section{Referencias}

Feldman, L., Goncalves, L., Chacón-Puignau, G., Zaragoza, J., Bagés, N. y de Pablo, J. (2008). Relaciones entre estrés académico, apoyo social, salud mental y rendimiento académico en estudiantes universitarios venezolanos. Univ Psychol, 7(3), 739-751.

García, C. (2005). Habilidades sociales, clima social familiar y rendimiento académico, en estudiantes universitarios. $\mathrm{Li}$ berabit, 11, 63-74. 
Huaquín, V.R. y Loaíza, R. (2004). Exigencias académicas y estrés en las carreras de la Facultad de Medicina de la Universidad Austral de Chile. Estudios Psicológicos, 30, 39-59.

Marty, C., Matías, G., Figueroa, M., Larraín, D y Cruz, M. (2005). Prevalencia de estrés en estudiantes del área de la salud de la Universidad de los Andes y su relación con enfermedades infecciosas. Revista Chilena de Neuropsiquiatría, 43(1), 25-32.

Paz, L., Rodríguez, P. y Martínez, M. (2009). Funcionamiento familiar de alumnos con bajo rendimiento escolar y su comparación con un grupo promedio de una preparatoria de la Universidad de Guadalajara. Revista de Educación y Desarrollo, 10, 5-15.

Petra, T., Espinosa, R., Esquivel, J. y Valle, L. (2006). Análisis de la estructura familiar en un grupo de médicos internos de pregrado de la Ciudad de México. Archivos en Medicina Familiar, 8(1), 75-80.

Valenzuela, L. y Fraijo, B. (2011). Integración y estrés en estudiantes universitarios. Ponencia en el XI Congreso Nacional de Investigación Educativa. Recuperado de: http:// www.comie.org. mx/congreso/memoriaelectronica/v11/ docs/area_16/2151.pdf. 